\title{
Escola na Rede:construindo uma comunidade eletrônica de aprendizagem
}

\author{
Fernanda Carneiro Leão Gonçalves* \\ Bayardo Joaquin Vega Morales**
}

\begin{abstract}
Resumo
O presente trabalho tem por objetivo apresentar o ambiente de educação a distância, o "Escola na Rede" da Secretaria da Fazenda do Rio Grande do Sul (SEFA/RS ), desenvolvido por sua Escola Fazendária (EFAZ). Esta ferramenta foi inteiramente desenvolvida e especificada, como um sistema proprietário, para atender não somente às necessidades de capacitação corporativa da SEFA/RS, mas também às demandas de outros órgãos, esferas governamentais, entidades e da sociedade em geral, que de alguma forma, se relacionam direta ou indiretamente com os serviços e atividades prestados por esta Secretaria.

Palavras-chave: Educação a distância, Escola na Rede, Secretaria da Fazenda SEFA/RS, Escola Fazendária, EFAZ.

\section{Abstract}

This paper aims to present the environment of the distance education program, named Escola na Rede, of the Secretaria da Fazenda do Rio Grande do Sul, Brasil (SEFA/RS), developed by Escola Fazendária (EFAZ). This tool was completely designed and developed, as an owner system, to supply not only the SEFA/RS corporative qualification needs, but the needs of the others agencies, other governamental levels, corporations and general society that, by some way, have a direct or indirect relationships with the services and activities provided by the SEFA/RS.
\end{abstract}

Key words: distance education, "Escola na Rede" , SEFA/RS.

\section{Diagnóstico do Cenário da Secretaria da Fazenda}

No contexto de qualificação de recursos humanos da SEFA/RS, constatamos, que ao longo dos últimos anos, os métodos e meios convencionais de treinamento não foram suficientes para atingir uma massa crítica de funcionários, ocasionando cumulativamente, uma defasagem de conhecimentos necessários para o desempenho eficiente e eficaz das atividades fazendárias.

Afirma (Drucker, 1993, p.18) que "a pessoa educada de amanhã deverá estar preparada para viver no mundo global(...). "Esse mundo global sobre o qual o autor aborda refere-se ao mundo do conhecimento, da criatividade, da cidadania, dos avanços tecnológicos, mas também da interação e da sensibilidade.

Paralelamente, no processo de Modernização como o que vem sendo desenvolvido pela SEFA/RS, contar com pessoal qualificado para executar adequadamente as tarefas de sua competência é um dos maiores desafios. A formação e desenvolvimento do quadro de funcionários de qualquer instituição ou empresa, dependem de um processo de aprendizagem que permita gerar perfis de competências, isto é, aptidões, conhecimentos, valores, atitudes e atributos pessoais, que contribuam para o desempenho bem-sucedido do trabalho.

Para uma adequada gestão do capital humano fazendário faz-se necessário incentivar a contínua aprendizagem e o melhoramento de desempenho, alinhados com os objetivos organizacionais. Isto só é possível se um programa de capacitação habilitar 
os funcionários a desenvolver seu potencial, reduzir a discordância entre as habilidades e conhecimentos e aqueles exigidos pelas suas funções.

Um moderno processo de capacitação e aprendizagem deve gerar atitudes positivas nos integrantes fazendários, facilitando a adaptação às contínuas mudanças que caracterizam a sociedade contemporânea.

Através de seu alinhamento estratégico, a SEFA/RS fez a opção de modernizar seus procedimentos administrativos, tanto das atividades-meio quanto das atividadesfim, com a utilização intensiva das novas tecnologias de informação e comunicação. Isto implica num significativo processo de mudança organizacional, o que depende fundamentalmente de uma concepção de treinamento e desenvolvimento que sensibilize e capacite o corpo funcional fazendário a conduzir este processo.

$\mathrm{Na}$ estrutura administrativa da SEFA/RS a Supervisão de Desenvolvimento Organizacional e Qualidade (SUDESQ) tem papel fundamental neste processo . Esta supervisão é composta por dois eixos de trabalho representados pelas duas divisões que a compõem: Divisão da Qualidade e Escola Fazendária (EFAZ). À Escola Fazendária , como responsável pelos programas de capacitação e desenvolvimento desta Secretaria, coube a função de coordenar, especificar, implementar, implantar e administrar o Projeto Escola na Rede.

O novo modelo deve estar harmonizado com as mutações do mundo contemporâneo, submetido ao choque da sociedade da informação, da mundialização e da civilização científica e técnica. Estes três choques básicos estão construindo uma nova sociedade: a sociedade do conhecimento. A geração de uma cultura organizacional direcionada para a aprendizagem contínua, portanto, é o grande desafio das organizações, tanto da iniciativa privada quanto do setor público.

Neste contexto, a EFAZ entende que , um Programa de Capacitação eficiente deve ter como desafio otimizar a gestão do conhecimento na organização, disponibilizando recursos de ensino-aprendizagem que habilitem o capital humano a implantar e gerenciar processos de modernização, bem como, que este conhecimento seja disponibilizado da forma mais abrangente possível. Como resultado desta reflexão, a EFAZ, concluiu que, estrategicamente, tais objetivos somente serão efetivamente alcançados com um projeto alicerçado em metodologias de Ensino a Distância.

Por outro lado, foi identificada, também, grande demanda estrutural na área de Educação Fiscal , compreendendo diversos públicos alvos : contabilistas, advogados, municípios, entidades de classe, sistemas de ensino da rede pública e privada; públicos estes que pela sua diversidade e amplitude, não poderão ser atendidos pelos meios convencionais de ensino presencial.

Segundo (Barreiros 2003) a sociedade organiza-se espacialmente de outra forma, onde a característica principal é a instantaneidade da informação, conquistada pelo avanço dos meios de comunicação (presentes nos diferentes aparatos tecnológicos) que, por meio de linguagens atraentes, aproximam os lugares, possibilitando uma tomada de conhecimentos imediatos e de acontecimentos simultâneos que criam entre os lugares uma relação que pretende apresentar unidade em escala global.

Desta forma, com o objetivo de atender e acompanhar as exigências desta "hova sociedade", foi desenvolvido um projeto de uma Escola de Ensino on-line da SEFA/RS , o "Escola na Rede" . Este, permite dar continuidade aos trabalhos de 
capacitação de pessoal, assim como atender às demandas emergentes. Configurou-se, desta forma, uma alternativa para disseminação/construção de conhecimento, fazendo uso das Tecnologias de Educação a Distância, aliadas aos métodos presenciais, através de ferramentas especialmente construídas, e uma ação sistemática e conjunta de diversos recursos didáticos, que tenham características próprias, independentes e autoadminstráveis por uma equipe de especialistas .

\section{Metodologia de Trabalho}

Para a especificação das funcionalidades e recursos de um sistema que atendesse a todas as necessidades e requisitos levantados, foi efetuada uma pesquisa qualitativa e quantitativa dos principais sistemas de educação a distância disponíveis e em funcionamento nos mais diferentes ambientes organizacionais, bem como uma análise de propostas recebidas de diversos fornecedores. Esta análise e avaliação foram realizadas por especialistas da própria SEFA/RS em Tecnologia da Informação e Educação a Distância, através da aplicação de um instrumento especialmente elaborado para esta finalidade. Na construção do instrumento foram especificadas todas as ferramentas definidas como necessárias para um sistema de EAD. Estas ferramentas foram agrupadas e classificadas, recebendo uma ponderação individual e por grupo, em função do grau de importância atribuído dentro de um sistema de EAD, e que também pudesse ser utilizado como ferramenta para gestão do conhecimento.

Entre os sistemas avaliados, não foi encontrado nenhum que atendesse satisfatoriamente todos os requisitos estabelecidos, razão pela qual, optou-se pelo desenvolvimento de um sistema específico e proprietário que atendesse a todas as funcionalidades e recursos desejáveis.

Após as definições e especificações procedeu-se à contratação de consultorias especializadas nas áreas pedagógica e tecnológica para implementação e implantação do sistema.

$\mathrm{Na}$ construção do sistema foi adotado o conceito de portal horizontal onde estão inseridos os principais componentes e funções, funcionando também como um repositório de conhecimentos permitindo o acesso e recuperação .

\section{Diretrizes Pedagógicas do Projeto de EAD da SEFA}

O cenário social, tecnológico, político e econômico sofreu grandes mudanças neste final de século promovendo o surgimento de novas atividades, ao mesmo tempo em que outras funções desaparecem ou foram transformadas. O crescimento exponencial do volume de informação, a geração de novos produtos, o advento de novas teorias ou a nova aplicação de teorias já largamente conhecidas, têm acarretado constantes reavaliações do processo de trabalho. A informática está se desenvolvendo de forma tão rápida e caótica, que se torna cada vez mais difícil ao sujeito, compreender e acompanhar as mudanças da tecnologia digital. Atualmente, o conceito chave desta nova era é a cooperação entre os sujeitos e a comunicação, eliminando distâncias, aproximando as pessoas e aumentando a produtividade através de métodos cooperativos/colaborativos de trabalho virtual.

Essa nova realidade redefine o perfil do sujeito deste novo século. É preciso formar profissionais que aprendam de forma não convencional e que saibam trabalhar cooperativamente para gerar soluções inovadoras e competitivas. $\mathrm{O}$ ensino tradicional não tem dado condições aos sujeitos de se prepararem no tempo adequado a todas essas 
transformações. Educação ainda está associada com treinamento, repasse de informações, baseada fisicamente em instituições, restrito a cronogramas pré-definidos de cursos. Esta estrutura não está preparada para os indivíduos que vivem na era do conhecimento.

Portanto, levando estas idéias à SEFA/RS, cabe forjar o novo sujeito que será capaz de participar ativa e criativamente deste processo de transformação, criticá-lo e refiná-lo. Logo, o ambiente educacional precisa se reorganizar para incluir em seu sistema uma pedagogia, metodologias, técnicas, recursos, estratégias de aprendizagem que permitam um novo paradigma que substitua a competição (alienante e individualizante) pela cooperação entre os sujeitos, a transmissão pela construção e o físico pelo virtual.

O principal objetivo do ambiente de EAD da SEFA/RS é trabalhar com tecnologias de rede aplicadas à educação como uma possibilidade para construção de um novo modelo educacional.

(Barreto, 2003) ao referir-se ao sentido da presença e aos modos de incorporação das tecnologias aos espaços educativos, conclui que é preciso pensar a apropriação das novas tecnologias na perspectiva da articulação de linguagens. É preciso repensar as práticas de linguagem desenvolvidas nos espaços educativos. É preciso redimensionar os padrões de interação nas salas de aula: romper com a repetição da palavra autorizada/consentida, no sentido de tornar mais significativas as práticas pedagógicas.

Logo, este ambiente está planejado para possibilitar a comunicação interativa entre grupos de educação presencial e grupos de educação não formal de forma síncrona e assíncrona. Os recursos utilizados no referido ambiente estão sendo implementados com o fim de desenvolver no indivíduo novos talentos, atitudes, mecanismos cognitivos e até mesmo novos valores.

Assim, foi construída uma plataforma que apóia este tipo de atividade, favorecendo a aprendizagem dos sujeitos, explorando características da Web como a autoria, a troca e a possibilidade de interação com pessoas, estejam elas onde estiverem.

Tendo em vista este panorama, e a necessidade de levar a cultura de aprendizagem para os funcionários da SEFA/RS, são apresentadas a seguir algumas características básicas que direcionam a construção, utilização e validação do ambiente de EAD da SEFA/RS:

O Foco é na construção, capacitação, aprendizagem, desenvolvimento das competências e habilidades, respeito ao ritmo individual;

- Formação de comunidades de aprendizagem, redes de convivência, educação aberta e a distância, gestão do conhecimento;

- $\quad$ Enfase no processo de construção do conhecimento, autonomia, autoria;

- $\quad$ Interação;

Construção de um Espaço de cooperação, respeito mútuo, solidariedade; 


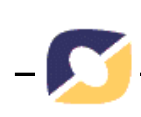

- $\quad$ Centrado na atividade do aprendiz, identificação e solução de problemas;

- $\quad$ Avaliação como processo;

- Pensamento em rede, não linear, rumo a um produtor de conhecimento;

- Requer Auto-organização e autodisciplina por parte do aprendiz;

\section{Conceitos-chave do modelo proposto}

$\mathrm{O}$ ambiente de EAD da SEFA/RS é uma proposta que busca responder às necessidades de um novo paradigma educacional. Logo, foi criado um ambiente especialmente para a aprendizagem, um lugar rico em recursos por ser um lugar privilegiado, onde os sujeitos possam construir os seus conhecimentos, segundo os "estilos" individuais de aprendizagem. Portanto, este novo tipo de ambiente de aprendizagem caracteriza-se pela cooperação, interatividade, individualização da aprendizagem, assincronia e/ou sincronia, não-linearidade (maneira mais dinâmica e atual de apresentar informação), entre outros. É privilegiada a produção em grupo em detrimento do trabalho individual. Através de estratégias para valorizar e fomentar a interação entre sujeitos, neste ambiente os sujeitos podem desenvolver habilidades de trato social, valorizando a interação produtiva entre eles.

Portanto, as diretrizes pedagógicas do ambiente de EAD da SEFA/RS, seguem um enfoque relacionado com um novo paradigma de aprendizagem, de acordo com a proposta pedagógica construtivista de Piaget, algumas idéias do Maturana e dos quatro pilares da educação, preconizados pela UNESCO.

Ensino a Distância, é definido pela (Unesco, 1987) como sendo uma 'variedade de programas educacionais e atividades...[onde] o aluno e o professor estão separados geograficamente...[mas] esforços são feitos para superar esta separação através da utilização de diferentes mídias.” •

Em primeiro lugar, o "Design" do ambiente de aprendizagem construído para a SEFA/RS é o resultado de uma pesquisa realizada sobre novas possibilidades de aplicação do potencial interativo das ferramentas telemáticas. Desta resultou um ambiente que está centrado na aprendizagem contextualizada e cooperativa. A Metodologia do mesmo é interativa e problematizadora usando, basicamente, como instrumento de trabalho, a pesquisa e a manipulação da informação para sua interpretação e representação, constituindo o que se chama de conhecimento. As atividades realizadas serão direcionadas para fazer com que os alunos aprendam a pensar, a aprender, a fazer perguntas. Enfim, a interagir com tudo e com todos, construindo o espírito de equipe e o trabalho em grupo.

É preciso definir os conceitos que fundamentam pedagogicamente o ambiente:

\section{Aprendizagem}

Para definir a concepção de aprendizagem utilizada no ambiente, foram utilizadas as idéias do Maturana que afirma que "aprender é uma modificação estrutural 
da convivência", ou seja, um encontro entre duas ou mais pessoas. Isso significa que deverá existir uma transformação no pensar e no interagir, através da troca, isto é, na forma de lidar com o "outro" e consigo mesmo. Neste caso, o encontro não é presencial e, sim, virtual. Portanto, foi preciso construir formas de "encontros virtuais" e de espaços de convívio através do ambiente. Estes espaços são os que possibilitam a construção do conhecimento dos tele-aprendizes.

Neste ambiente, Aprendizagem é considerado um fenômeno interno do sujeito e, é ele quem vai se apropriar ou não das informações recebidas e de que maneira, portanto não pode ser imposta.

Um dos principais objetivos do ambiente de EAD da SEFA/RS é oferecer recursos que potencializem ao aprendiz a aprendizagem, formando um aluno com idéias próprias.

Assim, os fundamentos destas idéias podem ser baseados também em Bruner que compara a educação com um processo de montagem de andaimes na construção do conhecimento (Bruner, 1997). Logo, estes processos são aqueles em que os professores, neste ambiente denominados de orientadores, proporcionam uma consciência aos alunos, visando ampliar e estender suas possibilidades. Desta forma, o professor oferece um apoio que permite ao tele-aprendiz avançar intelectualmente além do que poderia ter conseguido por si só. Em outras palavras, o professor se torna um companheiro da sua aprendizagem, através da criação contínua de conhecimento compartilhado.

\section{Características Gerais do Projeto}

* Formação de uma Comunidade Eletrônica de Aprendizagem

* Amplitude da Solução para Gestão do Conhecimento

* Autonomia na Geração dos Conteúdos/Cursos

* Utilização dos Padrões de Objetos de Aprendizagem

* Possui Completos Recursos de Parametrização

* Integração com Sistemas Corporativos da SEFA/RS

* Disponibilização de Recursos de Cooperação/Colaboração

\section{Benefícios Diretos Esperados} de pessoal;

- Aplicação constante, ininterrupta e personalizada da capacitação

- Possibilita a real gestão do conhecimento

- Desenvolver e compartilhar competências assim como reter colaboradores

- Redução direta de custos (deslocamento, material didático, com maior abrangência)

- Rápido retorno de investimento 
- Universalização da capacidade de treinamento sem perda da qualidade e com padronização

- Abrangência vinculada ao escopo da conectividade disponível

- Processo de dupla via de comunicação- cooperação/colaboração

Conforto e flexibilidade de tempo, local, fluxo, dinâmica e ritmo do processo de aprendizagem

- Facilidade de manter os conteúdos atualizados

- Redução do tempo de divulgação das informações

- Amplitude para toda a cadeia de relacionamentos.

\section{Fases do Projeto} fases.

O projeto "Escola na Rede" foi desenhado para ser desenvolvido em quatro

$1^{a}$ Fase- Disponibilização do sistema na rede interna (intranet) da SEFA/RS fase em implantação com o primeiro curso previsto para segunda quinzena de junho de 2003.

$2^{a}$ Fase- Disponibilização via Internet aos funcionários da SEFA/RS.

$3^{\text {a }}$ Fase- Disponibilização a outras Secretarias de Estado e órgãos públicos de diferentes esferas de governo.

$4^{\mathrm{a}}$ Fase- Disponibilização à comunidade em geral (advogados, contadores, associações de classe, rede de ensino pública e privada,).

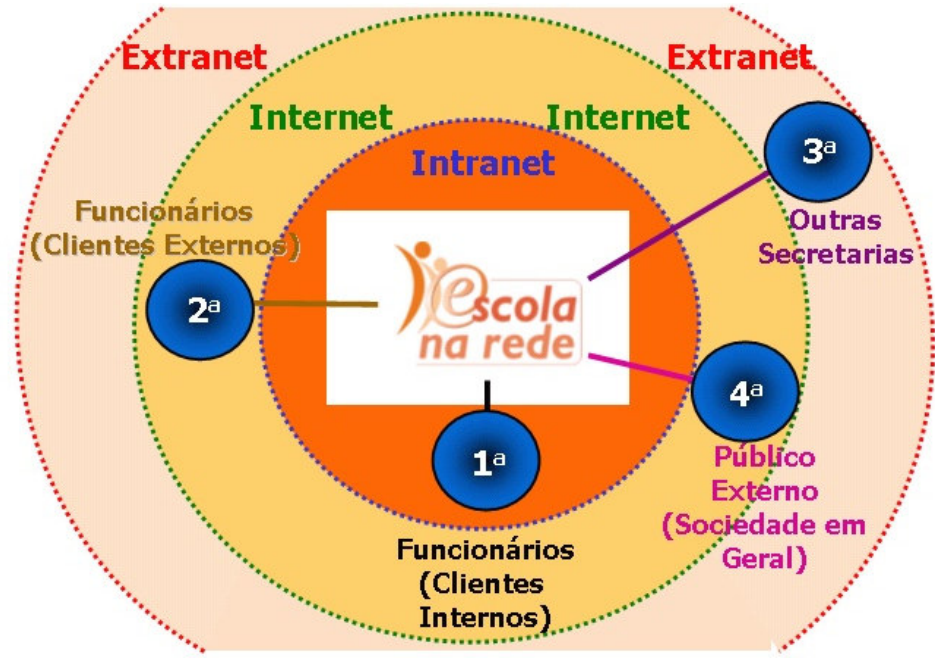

Fig.1 Etapas de implantação do projeto.

\section{Fatores Críticos de Sucesso}


$\mathrm{Na}$ elaboração do projeto foram relacionados os fatores críticos de sucesso, conforme relacionados abaixo

\subsection{Envolvimento dos Gestores}

Tem relação com o Organizacional e Estratégico- a alta diretoria necessita acreditar na idéia e dar suporte para sua implementação.

\subsection{Formação de uma Comunidade Eletrônica}

O projeto prevê a implantação de um sistema de educação a distância onde todos os elementos interajam entre si. Trata-se de uma cadeia de relacionamentos envolvendo os diferentes públicos-alvos que são interligados a partir da utilização de ferramentas de interatividade, coordenação e gestão do sistema.

\subsection{Desenvolvimento de um Planejamento Pedagógico}

O planejamento pedagógico estabelece as diretrizes do projeto de EAD. Nele são definidas as seguintes atividades:

- $\quad$ Regras e parâmetros de utilização do ambiente;

- $\quad$ Níveis de permissão, horários de utilização, pré-requisitos

- Concepção dos cursos: justificativas, objetivos, contexto e público alvo;

- Organização da Equipe Interna: integrantes, papéis e responsabilidades;

- Tratamento Pedagógico dos Conteúdos: planejamento instrucional (estrutura, elementos, técnicas e visual)

- Métodos de Avaliação dos Alunos: definição dos critérios de avaliação para cada contexto;

- Validação dos Materiais Produzidos:diretrizes para medições qualitativas e quantitativas.

\subsection{Adaptação da Cultura Organizacional}

* O papel do Aluno e do Professor;

* É essencial o Ajuste do Perfil de cada um.

* Desenvolvimento de autonomia na aprendizagem

* Valorização do estudo pelas chefias.

\subsection{Capacitação e Formação de Equipe Interna}

- $\quad$ Necessidade de talentos internos que possuam a função de gerenciar e viabilizar o ambiente; 


\subsection{Planejamento Instrucional}

- Combinação do Presencial e Não-Presencial-também conhecido como híbrido ou blended

- Usar o que cada um tem de melhor

- Identificar o que é mais apropriado para cada parte do Programa

\subsection{Estruturação do Conteúdo}

- Exigir a utilização do Conceito de Objetos de Aprendizagem: forma de armazenamento ;

- Maior Organização e Flexibilidade;

- Utilização de Padrões Técnicos reconhecidos (SCORM, AICC, IEEE);

\subsection{Sistema Proprietário}

- Código fonte da SEFA/RS sem licenciamento de terceiros, e que permite autonomia no gerenciamento dos recursos do sistema.

\subsection{Integração com Sistemas Corporativos já Existentes}

- $\quad$ Sistemas de Recursos Humanos / Histórico Escolar

- Gerenciamento de Competências:integração com a Matriz de Capacitação/SEFA

\subsection{Tecnologias}

topologias de rede;

- Sistemas de gerenciamento de conteúdos de aprendizagem: ambiente a parte, de acesso restrito a administradores.Tem por objetivo automatizar as tarefas de gerenciamento: registrar usuários, gerenciar matrículas, organizar o catálogo de cursos, analisar informações dos alunos, gerar relatórios gerenciais, etc...

- $\quad$ Ferramentas que possibilitam a geração de cursos a partir do próprio sistema.

- Configuração mínima das estações de trabalho para suportar as mídias e recursos previstos no projeto.

\section{Considerações Finais}


As necessidades de uma constante qualificação dos servidores públicos da SEFA/RS e de outros órgãos governamentais; a grande demanda estrutural existente na área de Educação Fiscal, compreendendo os mais diferentes públicos-alvos, justificou a busca de uma solução que fizesse uso das modernas tecnologias da informação e comunicação.

Através da implantação do sistema de Educação a distância 'Escola na Rede", torna-se possível atingir uma massa crítica de usuários que não poderia ser atendida por métodos tradicionais- presenciais. A partir de um projeto criterioso foram relacionados os fatores críticos de sucesso. Além disto , adotou-se como premissa básica, estabelecida no projeto pedagógico que o conhecimento é uma construção conjunta , fruto das interações dos indivíduos .

Para os próximos anos, conforme os quatro pilares definidos pela UNESCO, mais do que possuir a informação, os indivíduos precisam saber estabelecer relações: aprender a aprender, aprender a ser, aprender a interagir e aprender a fazer.

O ambiente encontra-se em plena produção. Já estão prontos os primeiros cursos, que atenderão funcionários da SEFA/RS em todo o estado: Gestão Pública, Contabilidade Prática I e Tecnologia da Informação. No cronograma estão previstos cursos de Officce, Direito Administrativo que deverão ser oferecidos até o final do ano.

As avaliações preliminares da utilização do ambiente, indicam que o sistema de EAD implantado corresponde às expectativas previstas no projeto.

O "Escola na Rede" é um sistema que foi especificado pela EFAZ visando a atender as necessidades de uma sociedade com crescentes demandas. As modernas ferramentas para interação síncrona, assíncrona desenvolvidas dentro de um conceito de portal, alavancadas por um sólido projeto pedagógico, possibilitarão também, sua utilização como um instrumento de gestão do conhecimento.

\section{REFERÊNCIAS}

BARREIROS, Débora. Redes Culturais diversidade e educação. Rio de Janeiro: DP\&A Editora. 2003; BARRETO, Raquel Goulart. Subjetividade, tecnologias e escolas. Rio de Janeiro: DP\&A Editora. 2003.

BARRETO, Raquel Goulart. Tecnologias Educacionais e Educação a

Distância: avaliando políticas e práticas. Rio de Janeiro, 2001.

BRUNER, J. Atos de significação. Porto Alegre: Artes Médicas, 1997.

DRUCKER, Peter F. (1993). A ascensão da sociedade do conhecimento; trad.

José Lívio Dantas. In: Diálogo 3 (27). São Paulo, 1994. p. 13-18. 
UNESCO. (1987). Distance Learning System and Structures: Training Manual, Report of a Sub-regional Training Workshop, Vol. II, Bangkok. 